\title{
Fast liquid chromatography-tandem mass spectrometry methodology for the analysis of alkylphenols and their ethoxylates in wastewater samples from the tank truck cleaning industry
}

Mélanie Mignot ${ }^{1}$, Maarten Nagels ${ }^{2}$, Sven Poelmans ${ }^{3}$, Alexander Kensert ${ }^{1}$, Jan Dries ${ }^{3}$, Raf Dewil $^{2}$, Deirdre Cabooter ${ }^{1^{*}}$

${ }^{1} \mathrm{KU}$ Leuven, Pharmaceutical Analysis, Faculty of Pharmaceutical Sciences, O\&N II Herestraat 49, Leuven, Belgium

${ }^{2} \mathrm{KU}$ Leuven, Department of Chemical Engineering, Process and Environmental Technology Lab, J. De Nayerlaan 5, B-2860 Sint-Katelijne-Waver, Belgium

${ }^{3}$ University of Antwerp, Bio-Chemical Green Engineering \& Materials, Faculty of Applied Engineering, Salesianenlaan 90, 2660 Antwerp, Belgium

$\left({ }^{*}\right)$ corresponding author:

tel.: (+) 32 (0)16.32.34.42, fax: (+) 32 (0)16.32.34.48, e-mail: deirdre.cabooter@kuleuven.be 


\section{Abstract}

A fast methodology to quantify 4-tert-octylphenol and 4-nonylphenol and their monoand di-ethoxylates was developed, validated, and applied to real wastewater samples. Dispersive liquid-liquid microextraction was employed as a sample preparation step, leading to a pre-concentration factor of roughly 30. Analysis was carried out by liquid chromatography-tandem mass spectrometry with electrospray ionisation in multiple reaction monitoring mode. Average recoveries were generally comprised between 80 and $120 \%$ for both the alkylphenols and their mono- and di-ethoxylates in influent and effluent wastewater. A minimum of 5 concentration levels per compound, ranging between 1 and $500 \mathrm{ng} / \mathrm{mL}$, were prepared to construct calibration curves making use of isotopically labelled internal standards. The method presented good linearity and repeatability over the whole range of concentrations. Taking into account the concentration factor, and the recovery of the compounds during sample preparation, lower limits of quantification obtained in effluent wastewater were $0.04 \mathrm{ng} / \mathrm{mL}$ for 4 -tOP and $0.14 \mathrm{ng} / \mathrm{mL}$ for 4-NP, complying with European regulations, and between 0.03 $\mathrm{ng} / \mathrm{mL}$ and $0.39 \mathrm{ng} / \mathrm{mL}$ for the ethoxylates. In influent wastewater, these limits were slightly higher. The total run time of $5 \mathrm{~min}$ for the alkylphenols, and $8 \mathrm{~min}$ for the ethoxylates ensured high throughput. The developed method was applied to determine 4-tert-octylphenol and 4-nonylphenol and their mono- and di-ethoxylates in wastewater from several tank truck cleaning companies, which was subjected to ozonation and/or biological treatment. It was demonstrated that ozonation is best applied after the biological treatment, since in this case the biological treatment can degrade most of the biodegradable organic matter, after which ozone can react directly with the recalcitrant organic pollutants. In this case, the concentrations of the target compounds in the wastewater of the investigated company decreased below the legally allowed concentration of the European water legislation.

Keywords: alkylphenol, alkylphenol ethoxylate, dispersive liquid-liquid microextraction, liquid chromatography-tandem mass spectrometry, wastewater, tank truck cleaning sector 


\section{Introduction}

Alkylphenols are a large family of organic compounds composed of a phenolic ring, substituted with an alkyl chain ( $n=1-12)$. The position of this alkyl chain can be at 3 different locations on the phenolic ring, leading to 2-, 3-, 4-alkylphenols. Among the alkylphenols, 4-octylphenols (4-OP) and 4-nonylphenols (4-NP) are used for a large number of industrial applications, such as the manufacturing of plastics, textile and agricultural products [1]. As precursors of alkylphenols, alkylphenol polyethoxylates (APEO) with an average number of 3-10 ethoxylate units and an alkyl chain length of eight (for octylphenol ethoxylates) or nine (for nonylphenol ethoxylates (NPEO)) carbon atoms are widely used industrially as non-ionic surfactants for detergents, antioxidants, dispersants and solubilizers [2]. As an example, the overall amount of NPEO manufactured and/or imported in the EU is in the range of $10.000-50.000$ tons/year [3]. Although it was completely banned as a cleaning agent in the EU from 1996 onwards, it is still used for other purposes in various industrial sectors (e.g., for fiber lubrication and dye levelling in the textile industry).

The tank truck cleaning sector deals with the internal cleaning of tanks and containers that are used to transport a variety of products, such as chemicals, paints, food products and soaps or surfactants [4]. Some of the transported products contain nonionic surfactants, typically including alkylphenol ethoxylates. These non-ionic surfactants are rather viscous, and therefore form a sticky layer at the inner wall of the tanks after their content has been discharged. Since it is very hard to remove this residual load before the actual cleaning process takes place, residues of these alkylphenol ethoxylates are rinsed off during the cleaning process and inevitably end up in the wastewater treatment plant of the tank truck cleaning company. Most tank truck cleaning companies have their own wastewater treatment plant with installations that can be adjusted to the type of wastewater collected. In most cases, the wastewater is subjected to the following unit operations: oil separation, physico-chemical treatment to remove colloidal particles, biological treatment, flotation or secondary clarifier (to separate the activated sludge of the biological reactor from the water), active carbon filter (if necessary), sand filter, and then discharge [5]. Despite these efforts, the presence of residual loads (i.e. alkylphenol ethoxylates or derivatives) has been reported in different water ecosystems, due to an incomplete removal from wastewater treatment plants $[6,7,8]$. 
Unlike biodegradable products that are efficiently removed, recalcitrant organic pollutants can accumulate, or be transformed into degradation products during wastewater treatment. Different pathways of biodegradation have been proposed depending on the conditions (aerobic versus anaerobic) but in general, alkylphenol polyethoxylates are transformed into alkylphenol carboxylates and alkylphenol ethoxylates with a shorter alkyl chain, and finally into alkylphenols [9]. Branched and linear isomers can occur, but contrary to the branched ones, linear 4-octylphenol and 4-nonylphenol (4-n-OP and 4-n-NP) are only scarcely used for industrial applications. The sources of alkylphenols in the environment are mainly effluent from sewage treatment plants, industrial waste discharge, and effluent from wastewater treatment plants, such as those linked to the tank truck cleaning industry [10,11]. The persistence and estrogenic activity of APEOs and some of their biodegradation products is now well-known. NP and OP can mimic natural hormones and their presence in the environment may disrupt endocrine functions in wildlife and humans [12]. Especially, nonylphenol was found to mimic the natural hormone $17 \beta$-estradiol by competing for the binding site of the oestrogen receptor [13]. Toxic effects of NP have been observed in fish, invertebrates, and mammals [14], and may also be involved in breast cancer increases and sperm count declines in humans [15]. In order to protect the environment and preserve the public safety, 4-tert-octylphenol (4-t-OP) and 4-NP have been included in the list of 45 priority substances set in the new European water legislation (Directive 2013/39/EU) [16].

To analyse these compounds in environmental water bodies, liquid chromatography has become the reference technique especially when combined with mass spectrometry (MS) to ensure high selectivity and sensitivity, even in complex matrices. A number of recent reviews on recent advances in environmental analysis [17], and on current approaches for the determination of alkylphenols and endocrine-disrupting compounds [1, 18] demonstrate that between 2002 and 2006, the most commonly employed extraction techniques for these compounds were liquid-liquid extraction (LLE) and solid phase extraction (SPE). From 2006 onward, more environmental friendly strategies have been developed based on microextraction techniques. Among the sorbent-based microextraction techniques, solid-phase microextraction (SPME) [19], stir-bar sorptive extraction (SBSE) and microextraction by packed sorbent (MEPS) have been used for environmental applications [20, 21, 22], but less for the 
determination of alkylphenols and bisphenol A [1]. Regarding LLE techniques, classic LLE has been replaced by liquid-liquid microextraction techniques (LLME), which minimize time- and reagent consumption according to green chemistry principles. Up to date, the most employed LLME procedure for the determination of alkylphenols and bisphenol $A$ is dispersive liquid-liquid microextraction (DLLME) [1, 23, 24]. DLLME, firstly introduced in 2006 by Rezaee et al. [25], relies on the use of an adequate mixture of extraction solvent and dispersant agent to produce a cloudy solution and extract the analytes. It is a fast and simple technique that minimizes the waste of organic solvent, thus being in accordance with the principles of green chemistry. This low cost technique allows to obtain high enrichment factors, but the main problem is the correct selection of solvents to avoid compound losses. Some authors have suggested to avoid the dispersant agent and use an adequate extraction solvent and an agitation step to form the cloudy solution [26]. DLLME has successfully been applied by Salgueiro-González et al. [23] for the determination of alkylphenols and bisphenol A in seawater samples, and by Zgola-Grześkowiak [24] for the isolation and concentration of alkylphenols and their short-chained ethoxylates in water samples by liquid chromatography with fluorescence detection. The quantification limits obtained in the latter study where just low enough to comply with European regulations. To the best of our knowledge, the combination of DLLME as extraction technique, and LC/MS/MS analysis for the determination of both octyl- and nonylphenol and their mono- and diethoxylates in complex matrices such as (treated) wastewater samples, has not been demonstrated yet.

The aim of this work was to develop a fast, simple and sensitive method allowing the quantification of 4-tert-octylphenol, 4-nonylphenol and their mono- and di-ethoxylates at levels in agreement with legislation. The applicability of the method for the analysis of real samples was demonstrated for wastewater collected at different stages of wastewater treatment plants managing sewage from the tank truck cleaning industry. To improve the degradation of these target compounds in current wastewater treatment schemes, the potential of ozonation as an advanced oxidation process (AOP) was subsequently evaluated. Finally, the application of ozonation in combination with a biological treatment was investigated and the optimal order of ozonation and biological treatment (i.e. AOP on influent followed by biology on the treated influent or biological treatment followed by AOP) determined. 


\section{Materials and methods}

\subsection{Standards and reagents}

All standards were purchased from Sigma-Aldrich (Steinheim, Germany): a nonylphenol technical mixture at $5 \mu \mathrm{g} / \mathrm{mL}$ (CAS 84852-15-3) in acetone, a 4-tertoctylphenol solution at $1 \mathrm{\mu g} / \mathrm{mL}$ (CAS 140-66-9) in acetone, an alkylphenol target analyte mixture in acetone containing 4-tert-octylphenol $1 \mu \mathrm{g} / \mathrm{mL}$ (4-t-OP), 4-tertoctylphenol-mono-ethoxylate $1 \mu \mathrm{g} / \mathrm{mL}$ (4-t-OP1EO), 4-tert-octylphenol-di-ethoxylate 1 $\mu \mathrm{g} / \mathrm{mL}$ (4-t-OP2EO), iso-nonylphenol, technical grade $5 \mu \mathrm{g} / \mathrm{mL}$ (4-NP), isononylphenol-mono-ethoxylate, technical grade $5 \mu \mathrm{g} / \mathrm{mL}$ (4-NP1EO), iso-nonylphenoldi-ethoxylate, technical grade $5 \mu \mathrm{g} / \mathrm{mL}$ (4-NP2EO), bisphenol A $1 \mu \mathrm{g} / \mathrm{mL}$. The structures of the analytes of interest are given in Figure 1.

As internal standards the following solutions at $10 \mu \mathrm{g} / \mathrm{mL}$ were obtained from SigmaAldrich (Steinheim, Germany): 4-(3,6-dimethyl-3-heptyl)phenol-ring- ${ }^{13} \mathrm{C}_{6}$ (CAS 1173020-38-6), 4-tert-octylphenol-ring- ${ }^{13} \mathrm{C}_{6}$ (CAS 1173020-24-0), 4-(3,6-dimethyl-3heptyl)phenol monoethoxylate-ring- ${ }^{13} \mathrm{C}_{6}$ (CAS 1173019-61-8) and 4-(3,6-dimethyl-3heptyl)phenol-diethoxylate-ring- ${ }^{13} \mathrm{C}_{6}$ (CAS 1173019-36-7). All stock solutions were kept at $-20^{\circ} \mathrm{C}$. Working standard solutions were obtained by diluting the stock solutions with methanol.

For the extraction, 1-octanol Chromasolv $\AA$ (grade HPLC 99\%) was from Sigma-Aldrich (Steinheim, Germany) as well as acetic acid. Methanol LC-MS grade and water LCMS grade were from VWR (Leuven, Belgium), and ammonia $7 \mathrm{~N}$ solution in methanol AcroSeal was from Fisher (CAS 7664-41-7) as well as ammonium acetate.

\subsection{Instrumentation}

LC analyses were carried out using an Infinity 1200 LC system (Agilent Technologies, Waldbronn, Germany) equipped with an autosampler, a binary pump, and a thermostated column oven. Analyst 1.5.2 version (AB Sciex) was used for instrument control, data acquisition and processing. The analyses were done on a Poroshell ECC18 (150 x $2.1 \mathrm{~mm}, 2.7 \mu \mathrm{m})$ column (Agilent Technologies). The injection volume was $5 \mu \mathrm{L}$, the temperature was set to $40^{\circ} \mathrm{C}$, and the flow rate was $0.2 \mathrm{~mL} / \mathrm{min}$. For the analysis of 4-t-OP and 4-NP, isocratic conditions were employed with a mobile phase consisting of $\mathrm{MeOH}+0.05 \%$ ammonia: $\mathrm{H}_{2} \mathrm{O} 90: 10(v / v)$. For the analysis of 4-t-OP1EO, 4-t-OP2EO, 4-NP1EO, 4-NP2EO, gradient conditions were selected with mobile 
phases: $(A)$ ammonium acetate $15 \mathrm{mM}+0.1 \%$ acetic acid and $(B) \mathrm{MeOH}$. The gradient was as follows: $80 \%$ (B) to $100 \%$ (B) in 1 min, this composition was maintained for 2 min and returned to the initial conditions in $0.5 \mathrm{~min}$. The system was re-equilibrated for 4.5 min between runs.

The LC instrument was coupled to a mass spectrometer with a triple quadrupole detector (API 3000, Applied Biosystems, Carlsbad, CA, USA), equipped with an electrospray probe working in negative mode for alkylphenols and in positive mode for the alkylphenol ethoxylates. MS/MS analysis was carried out using the Multiple Reaction Monitoring (MRM) mode for better sensitivity and specificity. Source dependent parameters were optimized in flow injection analysis (FIA) at $0.2 \mathrm{~mL} / \mathrm{min}$ using the mobile phase composition at which the compounds eluted. Compound dependent parameters were optimized by direct infusion of a diluted standard solution of each compound. The parameters are summarized in Table S1 in the Supporting Information. As internal standards, the isotopically labelled version of the molecules was used to ensure similar extraction recovery, ionization response in ESI MS, and retention time.

\subsection{Reduction of blank contamination}

Since nonylphenol is ubiquitous, various precautions were taken to avoid contamination with nonylphenol from external sources. Plastic materials were avoided as much as possible: amber glass containers were used to store the samples, samples were filtered with glass filters and all vessels were carefully cleaned, and rinsed with Milli-Q water and $\mathrm{MeOH}$ before use. LC-MS grade water was used for all experiments and procedural blanks were frequently performed.

\subsection{Sampling}

Real influent and effluent samples were taken at the full-scale wastewater treatment plants of several tank truck cleaning companies in Belgium. Companies 1 and 2 mostly clean tanks that transport chemical products (such as oil, toluene, epoxy resins, alkyl benzene sulfonic acids, poly carboxylates, paraffines and lubricants). Company 3 cleans tanks that contain chemical products such as toluene sulfonic acid, methane dicarboxylic acid, and "other products" such as Triton (alcohol ethoxylates), Tergitol (alkylphenol ethoxylates) and shower gel. Companies 4 and 5 mostly clean tanks that contain "end products" such as epoxy resins and even food products, such as 
chocolate (company 5). The samples were stored in amber glass containers and stored at $4^{\circ} \mathrm{C}$ until analysis.

\subsection{Extraction}

Samples were filtered on glass fiber filters from Macherey-Nagel (GF - 3; $0.6 \mu \mathrm{m}$ ) to remove any solid particles that could damage the system. 1-octanol (100 $\mu \mathrm{L})$ was added as extractant solvent to $30 \mathrm{~mL}$ of wastewater, as well as each internal standard at a concentration of $20 \mathrm{ng} / \mathrm{mL}$. The octanol droplets were dispersed by shaking at 100 rpm during 5 min with a Gemini BV heidolph Reax 2 mixer, and the two phases were separated by centrifugation at 3500 rpm during 3 min (Jouan B4 i Centrifuge, radius $161 \mathrm{~mm}$ ). The fine droplets of 1-octanol, containing the target compounds and the corresponding $\mathrm{C} 13$ internal standards, were collected and the volume was adjusted to $1 \mathrm{~mL}$ with methanol to make it miscible with the mobile phase. To evaluate potential contamination during the extraction procedure, procedural blanks (non-spiked water sample) were extracted following the same protocol.

\subsection{Validation}

A multilevel calibration was performed at 7 concentration levels for 4 -t-OP (1-100 $\mathrm{ng} / \mathrm{mL})$ and 4-NP (5-500 $\mathrm{ng} / \mathrm{mL})$, in methanol. For the ethoxylates, the calibration curves were constructed at 5 concentration levels $(5-100 \mathrm{ng} / \mathrm{mL})$ for 4 -t-OP1EO, 6 concentration levels $(10-500 \mathrm{ng} / \mathrm{mL})$ for 4-NP1EO, 7 concentration levels (1-100 $\mathrm{ng} / \mathrm{mL})$ for 4 -t-OP2EO and 8 concentration levels $(1-500 \mathrm{ng} / \mathrm{mL})$ for $4-N P 2 E O$, in methanol. Each sample was injected 5 times. For each compound, the corresponding internal standard was added at $20 \mathrm{ng} / \mathrm{mL}$ to correct for differences in ionisation and matrix effects. For 4-t-OP1EO and 4-t-OP2EO, 13C internal standards were not available in the laboratory. Therefore, 4-NP1EO 13C and 4-NP2EO 13C were used as internal standards, respectively.

The instrumental limits of detection (LOD) and quantification (LOQ) were determined by injecting solutions of decreasing concentrations. The LOD was considered as the lowest concentration point for which the signal-to-noise ratio $(S / N) \geq 3(n=5)$. The LOQ corresponded to the lowest concentration point for which the $S / N \geq 10$ and a good repeatability was obtained $(\mathrm{RSD}<10 \%, \mathrm{n}=5)$. 
Intra-day accuracy (recovery) and intra-day variability of the method were determined in influent and effluent wastewater of Company 2 at different concentration levels, injected three times each. For this purpose, $30 \mathrm{~mL}$ of influent or effluent wastewater was spiked with amounts of 4-t-OP, 4-t-OP1EO and 4-t-OP2EO ranging between 1 and $50 \mathrm{ng}$ and amounts of 4-NP, 4-NP1EO and 4-NP2EO ranging between 5 and 250 ng (see Table S2 in the supporting information). Non-spiked wastewater samples were analysed to assess background concentrations. The internal standard of each solute was added at $20 \mathrm{ng} / \mathrm{mL}$ to each sample. The solutions were extracted with $100 \mu \mathrm{L}$ of 1-octanol, and the final solution was diluted with methanol until $1 \mathrm{~mL}$. Recoveries were determined by subtracting the obtained peak areas (corrected for the IS) in non-spiked wastewater samples from the peak areas (corrected for the IS) obtained in the spiked samples, and comparing these values with the (corrected) peak areas obtained for the corresponding concentration in methanol (calibration curve samples). Note that the determination of the recovery in this way, assesses both analyte losses during the sample preparation and matrix effects.

Due to the limited availability of influent and effluent wastewater, inter-day accuracy (recovery) and inter-day variability of the method were determined in Milli-Q water at three concentration levels, by analysing three independent replicates on three different days, injected three times each. For this purpose, $30 \mathrm{~mL}$ of milli-Q water was spiked with 20, 50 or $75 \mathrm{ng}$ of 4-t-OP; 10, 20 or 50 ng of 4-t-OP1EO and 4-t-OP2EO; and 50, 100 or 250 ng of 4-NP, 4-NP1EO and 4-NP2EO. The internal standard of each solute was added at $20 \mathrm{ng} / \mathrm{mL}$. The solutions were extracted with $100 \mu \mathrm{L}$ of 1 -octanol, and the final solution was diluted with methanol until $1 \mathrm{~mL}$. Recoveries were calculated by comparing the peak areas (corrected for the IS) obtained for spiked milli-Q samples with the (corrected) peak areas for the corresponding concentration in methanol (calibration curve samples).

2.7 Advanced oxidation processes and biological treatment

Ozonation batch experiments were performed in a lab-scale glass reactor with a liquid volume of $1 \mathrm{~L}$. Ozone was generated from pure oxygen $\left(\mathrm{O}_{2}\right.$ Alphagaz 2, Air Liquide, Brussels, Belgium), by high voltage gas discharge tubes (corona discharge). The ozone generator (Anseros, Tübingen, Germany) had a maximum ozone capacity of 10 $\mathrm{g} \mathrm{O}_{3} / \mathrm{h}$ and could be adjusted between 10 and $100 \%$ of the maximum value. During the experiments, the ozone flow rate was fixed at approximately $5 \mathrm{~g} \mathrm{O}_{3} / \mathrm{h}$ at a total gas 
flowrate of $200 \mathrm{~L} / \mathrm{h}$. The produced ozone was transferred to wastewater contained in the lab-scale glass reactor via a stainless steel diffusor. During the ozonation, wastewater was continuously stirred by a magnetic mixer. Samples were taken at fixed time periods with a syringe, filtered on glass fiber filters and stored in amber glass containers at $4^{\circ} \mathrm{C}$ until analysis.

For the biological treatment, two lab scale activated sludge sequencing batch reactors were used. Both reactors were identical, with a height of $45 \mathrm{~cm}$ and a diameter of 20 $\mathrm{cm}$. The actual working volume was $6 \mathrm{~L}$, varying with the amount of influent fed $(0.5$ $\mathrm{L} / \mathrm{cycle}$ ). Each reactor performed 3 cycles/day, with every cycle consisting of a preparation phase $(0.5 \mathrm{~h})$, feeding phase $(30 \mathrm{~s})$, aerobic phase $(6.5 \mathrm{~h})$, settling phase $(1 \mathrm{~h})$ and discharge of effluent (5 min). Oxygen (LDO sensor, Hach, United States) and $\mathrm{pH}$ (sensor, Jumo, Germany) were constantly monitored, and data logging of the sensors was done with an sc1000 module (Hach, United States). The reactors were further equipped with a mixer (Heidolph Instruments, Germany), influent pump, and discharge valve. Aeration (on/off between 1-3 $\mathrm{mg} \mathrm{O}_{2} / \mathrm{L}$ ) was conducted with AquaForte (The Netherlands) air pumps using air stone balls for diffusion in the liquid. General operation of the reactors was done through the LabView ${ }^{\mathrm{TM}}$ software (National Instruments, United States) using a Siemens programmable logic controller (Germany). Reactors 1 and 2 were respectively fed with treated and non-treated influent from Company 2. Nutrients were added to the influent when nutrient requirements were not met $(\mathrm{COD} / \mathrm{N} / \mathrm{P}=100 / 2.5 / 0.8)$.

\section{Results and discussion}

\subsection{Optimization of LC/MS conditions}

For each compound, the most intense transition was used for quantification (quantifier) and the second one for confirmation of the identity (qualifier) (See Table S1 in the Supporting Information). Specific parent ions were [M - H] for 4-t-OP and 4-NP, and $\left[\mathrm{M}+\mathrm{NH}_{4}\right]^{+}$for 4-t-OP1EO, 4-t-OP2EO, 4-NP1EO, 4-NP2EO. Previous studies of alkylphenol ethoxylates favoured the use of sodium salts for quantitative LC/MS analysis because the affinity for this cation results in an abundant formation of stable $[\mathrm{M}+\mathrm{Na}]^{+}$adduct ions $[27,28]$. Nevertheless, these adducts are reluctant to fragmentation in the collision cell and cannot be used in MRM detection [29]. Consequently, an aqueous mobile phase consisting of $15 \mathrm{mM}$ ammonium acetate + 
$0.1 \%$ acetic acid was used to enhance the formation of ammonium adducts $\left[\mathrm{M}+\mathrm{NH}_{4}\right]^{+}$, which resulted in a reproducible fragmentation in the collision cell [29, 30, 31, 32, 11].

\subsection{Validation}

Over the entire range of studied concentrations (except at the LOQ where RSD $\leq 10 \%$ ), linear calibration curves with $R^{2}>0.996$ and average RSDs below $2 \%$ and $1 \%$ were obtained for 4-t-OP and 4-NP, respectively, and linear calibration curves with $\mathrm{R}^{2}>$ 0.999 and average RSDs lower than 5.6\% for 4-t-OP1EO, 3.9\% for 4 -t-OP2EO, 3.5\% for 4-NP1EO and 2.6\% for 4-NP2EO were obtained (Figure S1). After two months, 3 fresh calibration solutions were prepared at intermediate levels $(5,10,50 \mathrm{ng} / \mathrm{mL}$ for 4 $\mathrm{t}$-OP and 25, 50, $250 \mathrm{ng} / \mathrm{mL}$ for 4-NP) and the linear equation for both compounds was still consistent.

Considering a $S / N \geq 3(n=5)$ for the LOD and a $S / N \geq 10(R S D<10 \%, n=5)$ for the LOQ, instrumental LODs were $0.2 \mathrm{ng} / \mathrm{mL}$ for 4 -t-OP, 4-t-OP2EO, 4-NP2EO, $1 \mathrm{ng} / \mathrm{mL}$ for 4-NP, $2 \mathrm{ng} / \mathrm{mL}$ for 4 -t-OP1EO, and $5 \mathrm{ng} / \mathrm{mL}$ for 4-NP1EO, while instrumental LOQs were $1 \mathrm{ng} / \mathrm{mL}$ for 4-t-OP, 4-t-OP2EO, 4-NP2EO, and $5 \mathrm{ng} / \mathrm{mL}$ for $4-N P$, 4-t-OP1EO, and $10 \mathrm{ng} / \mathrm{mL}$ for $4-\mathrm{NP} 1 \mathrm{EO}$.

Intra-day accuracy (recovery) and intra-day variability of the method were determined in influent and effluent wastewater of Company 2 at different concentration levels, injected three times each. The average recoveries were generally comprised between 80 and 120\% (see Table S2 in the supporting information) for both the alkylphenols and the ethoxylates in influent and effluent wastewater, with a few outliers between 120 and $130 \%$. The exact values, together with the intra-day variability (expressed in terms of relative standard deviation (RSD)) are presented in Table S2. Average intraday RSDs were generally below $10 \%$ and always below $20 \%$. These results confirm that isotopically labelled compounds allow to compensate both for matrix effects and analyte losses during the extraction procedure and demonstrate the suitability of $\mathrm{MeOH}$ based calibration solutions to quantify levels in wastewater samples [34].

For effluent wastewater, intra-day accuracies were comprised between 81 and $121 \%$, with RSD values $\leq 20 \%$, at the instrumental LOQ. Taking into account the sample preparation step which concentrates the solutes by a factor of 30 , and the recovery for each compound, the method LOQ values were $0.04 \mathrm{ng} / \mathrm{mL}$ for 4 -t-OP and $0.14 \mathrm{ng} / \mathrm{mL}$ for 4-NP. These limits are satisfactory taking into account that the allowed 
environmental concentrations are $0.1 \mathrm{ng} / \mathrm{mL}$ for 4 -t-OP and $0.3 \mathrm{ng} / \mathrm{mL}$ for $4-\mathrm{NP}$ as mentioned by the directive 2013/39/EU of the European parliament and of the council of 12 august 2013 [16]. The ion extracted chromatograms at the limit of quantification for 4-NP and 4-t-OP are presented in Figure S2. For the ethoxylates, the method LOQ was $0.39 \mathrm{ng} / \mathrm{mL}$ for $4-N P 1 E O, 0.04 \mathrm{ng} / \mathrm{mL}$ for $4-N P 2 E O, 0.15 \mathrm{ng} / \mathrm{mL}$ for 4 -t-OP1EO and $0.03 \mathrm{ng} / \mathrm{mL}$ for 4 -t-OP2EO. The ion extracted chromatograms at the limit of quantification for 4-t-OP1EO, 4-t-OP2EO, 4-NP1EO and 4-NP2EO are presented in Figure S3.

For influent wastewater, acceptable intra-day accuracies could not be obtained at all instrumental LOQs for all compounds (see Table S2 in the supporting information). Therefore, the method LOQs are slightly higher in influent wastewater compared to effluent wastewater: $0.06 \mathrm{ng} / \mathrm{mL}$ for $4-\mathrm{t}-\mathrm{OP}, 0.14 \mathrm{ng} / \mathrm{mL}$ for $4-\mathrm{NP}, 0.28 \mathrm{ng} / \mathrm{mL}$ for 4 NP1EO, $0.92 \mathrm{ng} / \mathrm{mL}$ for $4-N P 2 E O, 0.29 \mathrm{ng} / \mathrm{mL}$ for 4 -t-OP1EO and $0.15 \mathrm{ng} / \mathrm{mL}$ for 4 -tOP2EO.

Due to the limited availability of influent and effluent wastewater, inter-day accuracy (recovery) and inter-day variability of the method were determined in Milli-Q water at three concentration levels, by analysing three independent replicates on three different days, injected three times each (for more details, see section 2.6-Validation). The average recoveries were comprised between $86.7-102.9 \%$ (see Table S3 in the supporting information) for the alkylphenols and between $87.6-95.1 \%$ for the ethoxylates. The exact values at the 3 levels of concentration, together with the intraday and inter-day variability (RSD) for all compounds are presented in Table S3. Average inter-day RSDs were between 2.8 and $5.9 \%$ for the alkylphenols and between 1.8 and $9.2 \%$ for the ethoxylates. Blank samples demonstrated the absence of contamination for all target compounds, at all levels of concentration studied.

\subsection{Analysis of real wastewater samples}

Real influent and effluent samples were taken at the full-scale wastewater treatment plants of tank truck cleaning companies located in Belgium. Effluent samples corresponded to wastewater obtained at the end of the wastewater treatment installation of each company (i.e. the water discharged into the environment), and influent samples corresponded to samples obtained before the biological reactor. 
The method was successfully applied for the analysis of 4-t-OP, 4-NP and its monoand di-ethoxylates. The extraction procedure was as described in section 2.5, each batch of $30 \mathrm{~mL}$ of samples being spiked with each internal standard at $20 \mathrm{ng} / \mathrm{mL}$ before extraction to correct for ionization differences due to the matrix. For 4-t-OP1EO and 4t-OP2EO, isotopically labelled 4-NP1EO and 4-NP2EO, respectively, were used as internal standards.

As an example, extracted ion chromatograms for 4-t-OP and 4-NP of influent water from Company 3 are depicted in Figure 2. In this sample, target analytes 4-t-OP, 4-NP were unequivocally identified according to their retention time and the mass transitions of the reference standards. Samplings were done at each company and influent and/or effluent waters were analyzed. The results are gathered in Table 1. As nonylphenol ethoxylates are more frequently used than octylphenol ethoxylates, it was expected to find that 4-NP is generally more present than 4-t-OP [33], and more concentrated in the influent than in the effluent indicating the different steps in the wastewater treatment are useful to decrease the nonylphenol concentration. Nevertheless, the concentrations found in the effluents of all companies were still too high to comply with European regulations $(0.1 \mathrm{ng} / \mathrm{mL}$ for 4 -t-OP and $0.3 \mathrm{ng} / \mathrm{mL}$ for $4-\mathrm{NP})$, necessitating the use of additional treatments, such as advanced oxidation processes, to meet the legal discharge limits.

\subsection{Advanced oxidation processes and biological treatment}

To further decrease the concentrations of 4-NP and 4-t-OP after regular wastewater treatment, an ozone treatment at $5 \mathrm{~g} / \mathrm{h}$ was first evaluated on different wastewater samples collected at 3 companies (Company 1, 2 and 3, see details in section 2.4Sampling). The concentrations obtained after $0,5,10,15,30$ min of treatment are presented in Table 2. As an example, more than $95 \%$ of the 4-NP concentration of the effluent of company 1 was removed after 30 min treatment. In all cases, ozonation allowed to degrade 4-NP and 4-t-OP with a removal rate depending on the nature of the wastewater and its initial concentration. Especially when applied to effluent wastewater, ozonation allowed to reduce the concentration of 4-NP and 4-t-OP close to the limits allowed by the European water legislation $(0.3 \mathrm{ng} / \mathrm{mL}$ for $4-\mathrm{NP}$, and 0.1 $\mathrm{ng} / \mathrm{mL}$ for 4 -t-OP). 
To evaluate at which stage and to what extent the ozonation is best applied in the wastewater treatment process (with regards to the biological treatment), three schemes were subsequently applied to a fresh sample of influent wastewater from company 2 (obtained on a different day compared to the sample analysed in Table 2). In these experiments, the biological treatment was simulated by a labscale sequencing batch reactor (SBR, $\pm 5 \mathrm{~L}$ ), inoculated with sludge. Ozonation was applied for $15 \mathrm{~min}$ on the influent before feeding the treated influent to the SBR (Scheme 1, Table 3), ozonation was applied for $30 \mathrm{~min}$ on the effluent of the biological treatment (Scheme 2, Table 3) and ozonation was applied for $60 \mathrm{~min}$ on the effluent of the biological treatment (Scheme 3, Table 3).

The resulting concentrations of 4-NP, 4-t-OP, 4-t-OP1EO, 4-t-OP2EO, 4-NP1EO and 4-NP2EO are presented in Table 3, and the extracted ion chromatograms of the influent water are depicted in Figure 3. All target molecules were drastically degraded by the combination of biological and ozone treatment, and the European legal discharge limits were reached when applying ozonation after the biological treatment (scheme 2 and 3), with a longer ozone treatment time (60 min instead of $30 \mathrm{~min}$ ) leading to a further degradation of all compounds. These experiments demonstrate that it is more effective (in terms of degradation efficiency) to perform the biological treatment before the ozone treatment. This is because the influent of the wastewater treatment contains a large amount of biodegradable organic matter. When ozone is applied to influent, it will also react with this biodegradable matter, leaving less ozone to react with the recalcitrant organic pollutants. When the biological treatment is applied first, it can degrade most of the biodegradable matter, allowing ozone to react directly with the alkylphenols and ethoxylates. Since ozonation is a rather expensive technique, it is most cost-efficient when applied as a polishing step after biological treatment.

\section{Conclusion}

In this project, a fast methodology to quantify 4-tert-octylphenol and 4-nonylphenol (5 min run time), and their mono- and di-ethoxylates (8 min run time) was developed, validated, and applied to wastewater from the tank truck cleaning sector. For this purpose, tank truck cleaning companies dealing with various types of products were 
sampled and analysed. The target compounds were extracted from the wastewater and concentrated by a factor of 30 using dispersive liquid-liquid microextraction. The samples were then analysed by liquid chromatography-tandem mass spectrometry with electrospray ionisation in multiple reaction monitoring mode. Recoveries, repeatability, and limit of quantification were satisfactory for all compounds, the latter being below the limits set by the European directives. The applicability of the method was demonstrated for real wastewater samples of various tank truck cleaning companies. For all companies, the concentrations of 4-t-OP and 4-NP in the effluent of the wastewater treatment were above the legal discharge limits set by the European regulations, demonstrating the need for additional treatment. For this purpose, ozonation as an advanced oxidation process was evaluated in combination with a labscale sequencing batch reactor inoculated with sludge. The optimal order of the ozonation and the biological treatment was evaluated and it was demonstrated that ozonation is particularly effective when used as a polishing step after the biological treatment.

In follow-up studies, the toxicity of the treated water will be evaluated after biological and ozone treatment. Alternative AOPs (e.g., $\mathrm{UV} / \mathrm{H}_{2} \mathrm{O}_{2}$, photo-Fenton process, etc) will be evaluated as well and the optimal set-up will be tested on a pilot plant to study the feasibility of the integrated wastewater treatment procedure for wastewater from the tank truck cleaning sector. 


\section{Acknowledgments}

This research was funded by the Flemish Government in the form of a technology transfer (TETRA) project (project no.: HBC.2017.0052: "Inteauclean: Integrated wastewater treatment in the tank truck cleaning sector"). Kris Wolfs is kindly acknowledged for his contribution to the scientific discussions regarding this study and Christophe Bries (AB Sciex) for his advice regarding the operation of the LC-MS. Ludovicus Staelens and Johan Nicolai of UCB Pharma (Belgium) are thanked for the kind gift of the triple quadrupole MS.

6. Conflict of Interest

The authors declare that they have no conflict of interest. 


\section{References}

[1] Salgueiro-González N, Muniategui-Lorenzo S, López-Mahía P, Prada-Rodríguez D. Trends in analytical methodologies for the determination of alkylphenols and bisphenol $A$ in water samples. Anal. Chim. Acta. 2017; 962: 1-14.

[2] Pothitou P, Voutsa D. Endocrine disrupting compounds in municipal and industrial wastewater treatment plants in Northern Greece. Chemosphere. 2008; 73: 1716-1723.

[3] Substance evaluation conclusion and evaluation report for nonylphenol, branched, ethoxylated. 2016. Online available: https://echa.europa.eu/documents/10162/13628/SEV-500-209-11_CONCLUSION_AND_REPORT_public_7547_en.pdf/34bf9b62-1499-18af-b059-4c8581b030cd. [Accessed 1811 2018].

[4] Caluwé M, Dobbeleers T, Daens D, Geuens L, Blust R, Dries J. SBR treatment of tank truck cleaning wastewater: sludge characteristics, chemical and ecotoxicological effluent quality. Environmental Technology. 2018; 39: 2524-2533.

[5] Dries J, De Schepper W, Geuens L, Blust R. Removal of ecotoxicity and COD from tank truck cleaning wastewater. Water Science and Technology. 2013; 68: 2202-2207.

[6] Bennie D. Review of the environmental occurrence of alkylphenols andalkylphenol ethoxylates. Water Qual. Res. J. Can. 1999; 34: 79-122.

[7] Soares A, Guieysse B, Jefferson B, Cartmell E, Leste J. Nonylphenol in the environment: a critical review on occurrence, fate, toxicity and treatment in wastewaters. Environ. Int. 2008; 34: 10331049.

[8] Ying G G, Williams B, Kookana R. Environmental fate of alkylphenols andalkylphenol ethoxylates - a review. Environ. Int. 2002; 28: 215-226.

[9] Sacco C, Pizzo A, Tiscione E, Burrini D, Messeri L, Lepri L, Bubba M. Alkylphenol polyethoxylate removal in a pilot-scale reed bed and phenotypic characterization of the aerobic heterotrophic community. Water Environ. Res. 2006; 78: 754-763.

[10] Ceśpedes R, Lacorte S, Ginebreda A, Barceló D. Occurrence and fate of alkylphenols and alkylphenol ethoxylates in sewage treatment plants and impact on receiving waters along the Ter River (Catalonia, NE Spain). Environ. Pollut. 2008; 153: 384-392.

[11] Loos R, Hanke G, Umlauf G, Eisenreich S. LC-MS-MS analysis and occurrence of octyl- and nonylphenol, their ethoxylates and their carboxylates in Belgian and Italian textile industry, waste water treatment plant effluents and surface waters. Chemosphere. 2007; 66: 690-699.

[12] Ahel M, McEvoy J, Giger W. Bioaccumulation of the lipophilic metabolites of nonionic surfactants in freshwater organisms. Environ. Pollut. 1993; 79: 243-248.

[13] Lee P, Lee W. In vivo estrogenic action of nonylphenol in immature female rats. Bull. Environ. Contam. Toxicol. 1996; 57: 341-348. 
[14] Staples C, Mihaich E, Carbone J, Woodbrun K, Klecka G. A weight of evidence analysis of the chronic ecotoxicity of nonylphenol ethoxylates, nonylphenol ether carboxylates, and nonylphenol. Human Ecol. Risk Assessment. 2004; 10: 999-1017.

[15] Blackburn M, Waldock MJ. Concentrations of alkylphenols in rivers and estuaries in England and Wales. Water Res. 1995; 29: 1623-1629.

[16] Directive 2013/39/EU of the European Parliament and of the Council of 12 August 2013 Amending Directive 2000/60/EC as Regards Priority Substances in the Field of Water Policy. 2013.

[17] Perez-Fernandez V, Mainero Rocca L, Tomai P, Fanali S, Gentili A. Recent advancements and future trends in environmental analysis: Sample preparation, liquid chromatography and mass spectrometry. Anal. Chim. Acta. 2017; 983: 9-41.

[18] Grześkowiak T, Czarczyńska-Goślińska B, Zgoła-Grześkowiak A. Current approaches in sample preparation for trace analysis of selected endocrine-disrupting compounds: Focus on polychlorinated biphenyls, alkylphenols, and parabens. Trends in Anal. Chem. 2016; 75: 209226.

[19] Jia Y, Su H, Wang Z, Wong Y, Chen X, Wang M, Chan T. Metal-organic framework@microporous organic network as adsorbent for solid-phase microextraction. Anal. Chem. 2016; 88: 93649367.

[20] Gilart N, Miralles N, Marcé R, Borrull F, Fontanals N. Novel coatings for stir bar sorptive extraction to determine pharmaceuticals and personal care products in environmental waters by liquid chromatography and tandem mass spectrometry. Anal. Chim. Acta. 2013; 774: 51-60.

[21] Benedé J, Chisvert A, Giokas D, Salvador A. Stir bar sorptive-dispersive microextraction mediated by magnetic nanoparticles-nylon 6 composite for the extraction of hydrophilic organic compounds in aqueous media. Anal. Chim. Acta. 2016; 926: 63-71.

[22] Haunschmidt M, Klampfl C, Buchberger W, Hertsens R. Determination of organic UV filters in water by stir bar sorptive extraction and direct analysis in real-time mass spectrometry. Anal. Bional. Chem. 2010; 397: 269-275.

[23] Salgueiro-González N, Concha-Graña E, Turnes-Carou I, Muniategui-Lorenzo S, López-Mahía P, Prada-Rodríguez D. Determination of alkylphenols and bisphenol A in seawater samples by dispersive liquid-liquid microextraction and liquid chromatography tandem mass spectrometry for compliance with environmental quality standards (Directive 2008/105/EC). J. Chromatogr. A. $2012 ; 1223: 1-8$.

[24] Zgola-Grześkowiak A. Dispersive liquid-liquid microextraction applied to isolation and concentration of alkylphenols and their short-chained ethoxylates in water samples. J. Chromatogr. A. 2010; 1217: 1761-1766.

[25] Rezaee M, Assadi Y, Milani Hosseini M, Aghaee E, Ahmadi F, Berijani S. Determination of organic compounds in water using dispersive liquid-liquid microextraction. J. Chromatogr. A. 2006; 1116: 1-9. 
[26] Zhang Z, Ohiozebau E, Rhind S. Simultaneous extraction and clean-up of polybrominated diphenyl ethers and polychlorinated biphenyls from sheep liver tissue by selective pressurized liquid extraction and analysis by gas chromatography-mass spectrometry. J. Chromatogr. A. 2011; 1218: 1203-1209.

[27] Ferguson $P$, Iden C, Brownawell B. Analysis of nonylphenol and nonylphenol ethoxylates in environmental samples by mixed-mode high-performance liquid chromatography-electrospray mass spectrometry. J. Chromatogr. A. 2001; 938: 79-91.

[28] Shang D, Ikonomou M, Macdonald R. Quantitative determination of nonylphenol polyethoxylate surfactants in marine sediment using normal-phase liquid chromatographyelectrospray mass spectrometry. J. Chromatogr. A. 1999; 849: 467-482.

[29] Schmitz-Afonso I, Loyo-Rosales J, Avilés M, Rattner B, Rice C. Determination of alkylphenol and alkylphenolethoxylates in biota by liquid chromatography with detection by tandem mass spectrometry and fluorescence spectroscopy. J. Chromatogr. A. 2003; 1010: 25-35.

[30] Houde F, DeBlois C, Berryman D. Liquid chromatographic-tandem mass spectrometric determination of nonylphenol polyethoxylates and nonylphenol carboxylic acids in surface water. J. Chromatogr. A. 2002; 961: 245-256.

[31] Takino M, Daishima S, Yamaguchi K. Determination of nonylphenol ethoxylate oligomers by liquid chromatography-electrospray mass spectrometry in river water and non-ionic surfactants. J. Chromatogr. A. 2000; 904: 65-72.

[32] Cohen A, Klint K, Bøwadt S, Persson P, Jönsson J. Routine analysis of alcohol and nonylphenol polyethoxylates in wastewater and sludge using liquid chromatography-electrospray mass spectrometry. J. Chromatogr. A. 2001; 927: 103-110.

[33] Sharma V, Anquandah G, Yngard R, Kim H, Fekete J, Bouzek K, Ray A, Golovko D. Nonylphenol, octylphenol, and bisphenol-A in the aquatic environment: $A$ review on occurrence, fate, and treatment. J. Environ. Sci. Health. 2009. 44; 423-442.

[34] López-García E, Mastroianni N, Postigo C, Barceló D, López de Alda M. A fully automated approach for the analysis of 37 psychoactivesubstances in raw wastewater based on on-line solid phaseextraction-liquid chromatography-tandem mass spectrometry. J. Chrom. A. 2018. 1576; 80-89. 


\section{Figure Captions}

Figure 1: Structures of the compounds studied in this work.

Figure 2: Extracted ion chromatograms of 4-t-OP, 4-t-OP (IS), 4-NP, 4-NP (IS) for influent of Company 3.

Figure 3: Extracted ion chromatograms of 4-t-OP1EO, 4-t-OP2EO, 4-NP1EO, 4NP1EO (IS), 4-NP2EO, 4-NP2EO (IS) for influent of Company 2. 


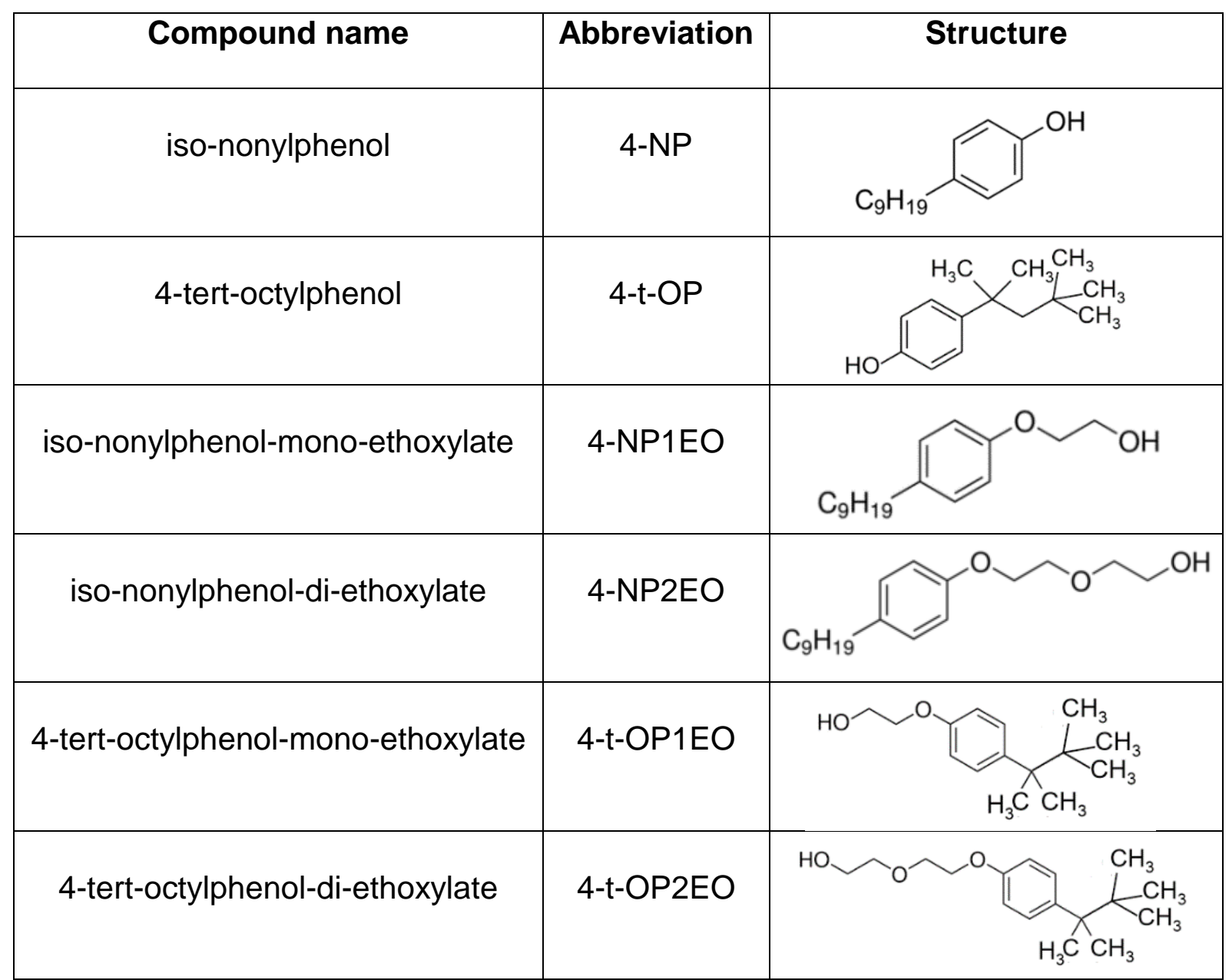

Figure 1 

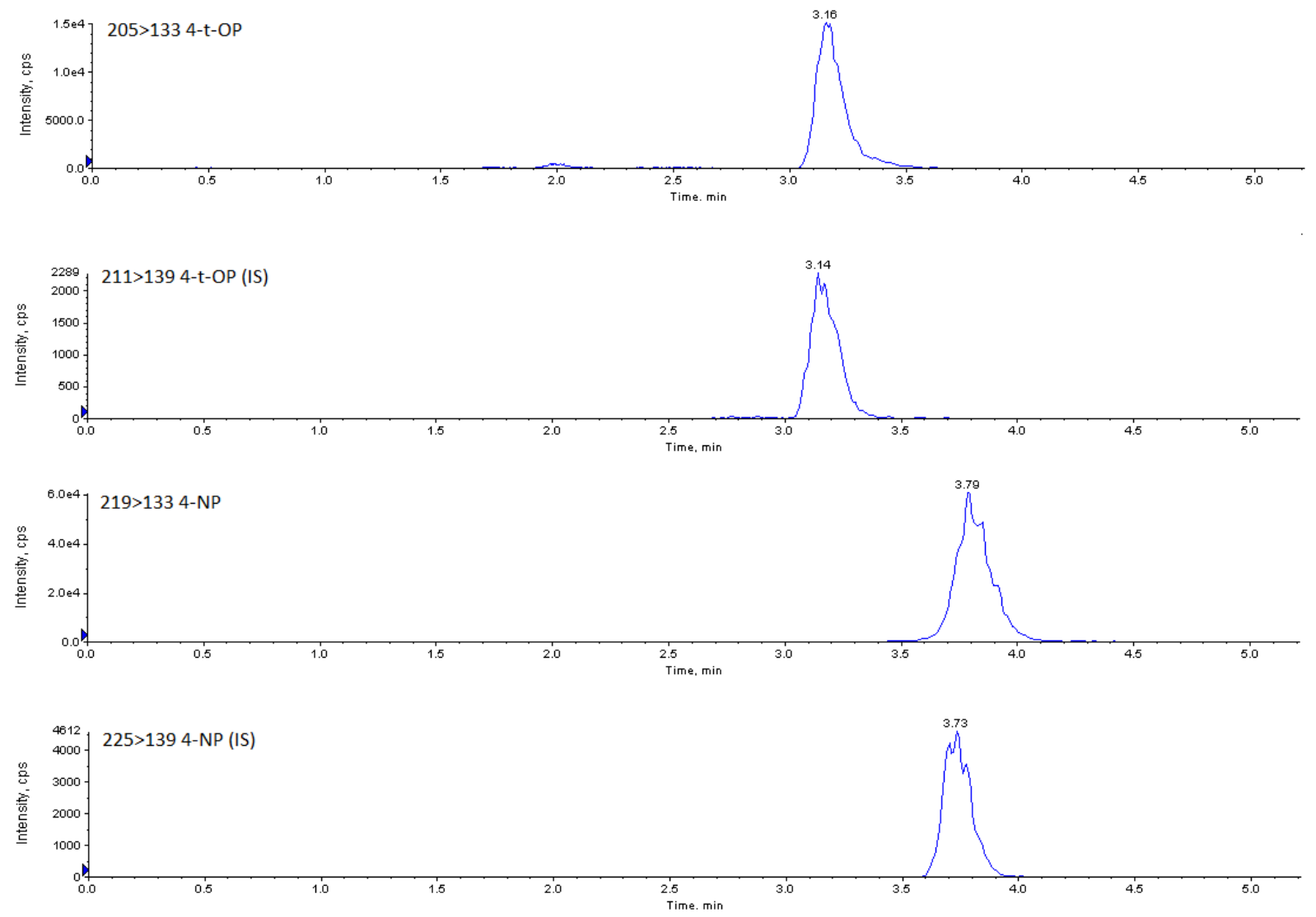

Figure 2 

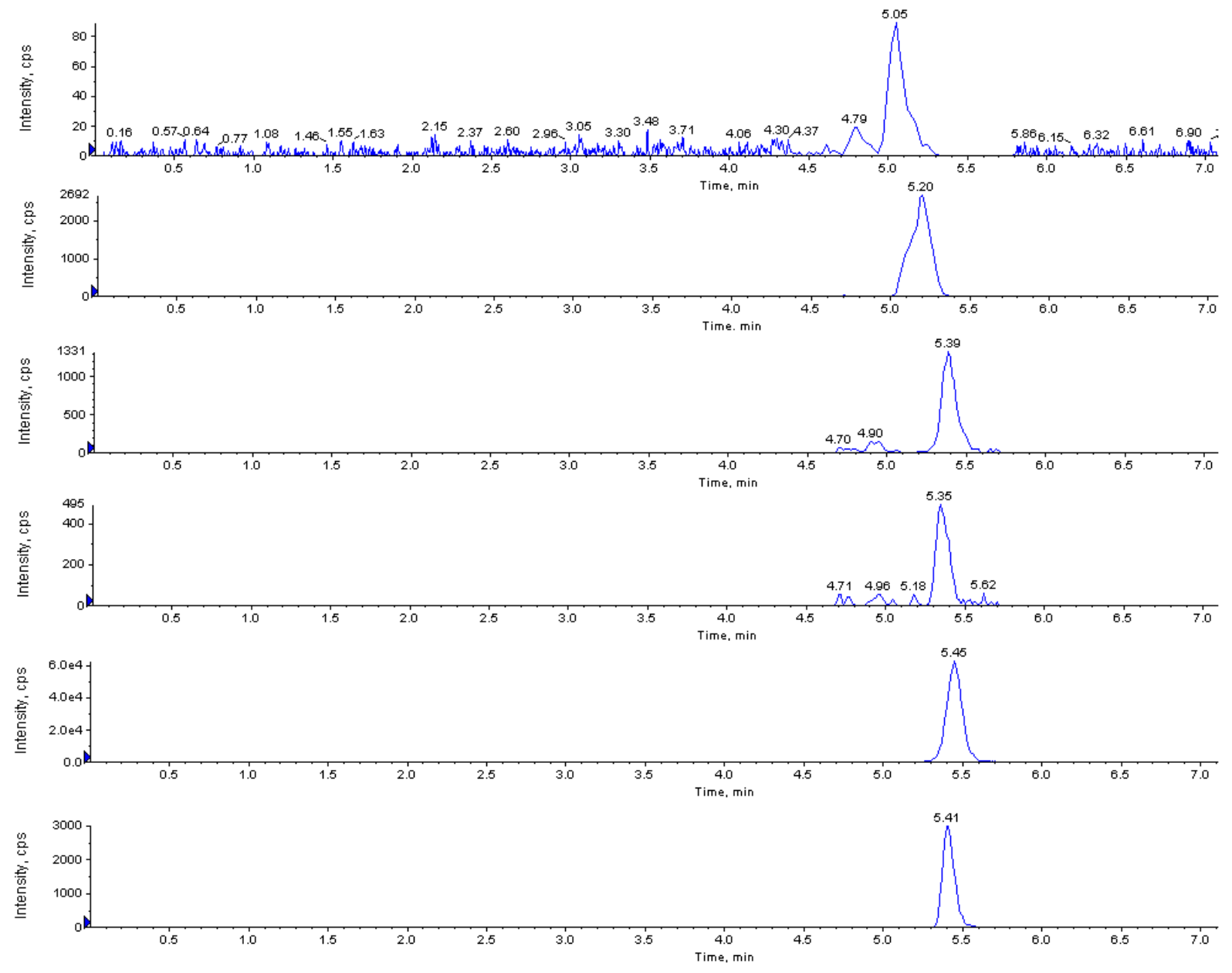

Figure 3 
Table 1: Concentrations of 4-t-OP and 4-NP in influent and effluent samples from different tank cleaning companies.

\begin{tabular}{|c|c|c|c|c|c|c|c|}
\hline & $\begin{array}{c}\text { Company 1 } \\
\text { effluent }\end{array}$ & $\begin{array}{c}\text { Company 2 } \\
\text { influent }\end{array}$ & $\begin{array}{c}\text { Company 2 } \\
\text { effluent }\end{array}$ & $\begin{array}{c}\text { Company 3 } \\
\text { influent }\end{array}$ & $\begin{array}{c}\text { Company 3 } \\
\text { effluent }\end{array}$ & $\begin{array}{c}\text { Company 4 } \\
\text { effluent }\end{array}$ & $\begin{array}{c}\text { Company 5 } \\
\text { effluent }\end{array}$ \\
\hline $\begin{array}{c}4-\mathrm{NP} \\
(\mathrm{ng} / \mathrm{mL})\end{array}$ & 21.6 & 7.1 & 1.1 & 16.4 & 3.7 & 17.8 & 4.0 \\
\hline $\begin{array}{c}4-\mathrm{t}-\mathrm{OP} \\
(\mathrm{ng} / \mathrm{mL})\end{array}$ & 0.4 & 1.0 & 0.3 & 5.5 & 0.1 & $/$ & $/$ \\
\hline
\end{tabular}

$(/)$ : value is under the limit of quantification 
Table 2: Concentrations of 4-t-OP and 4-NP in influent and effluent samples from different tank cleaning companies, before and after ozone treatment.

\begin{tabular}{|c|c|c|c|c|}
\hline $\mathrm{AOP}=\mathrm{O}_{3}\left(5 \mathrm{~g} \mathrm{O}_{3} / \mathrm{h}\right.$ applied $)$ & $\begin{array}{c}\text { Company } 1 \\
\text { effluent }\end{array}$ & $\begin{array}{c}\text { Company } 2 \\
\text { influent }\end{array}$ & $\begin{array}{c}\text { Company } 2 \\
\text { effluent }\end{array}$ & $\begin{array}{c}\text { Company } 3 \\
\text { effluent }\end{array}$ \\
\hline \multicolumn{5}{|l|}{ 4-NP (ng/mL) } \\
\hline $\mathrm{t}=0 \mathrm{~min}$ & 21.6 & 7.1 & 1.1 & 3.7 \\
\hline$t=5 \min$ & 2.5 & 8.0 & 0.2 & 0.7 \\
\hline $\mathrm{t}=10 \mathrm{~min}$ & n.a. & 4.9 & 0.2 & 0.5 \\
\hline $\mathrm{t}=15 \mathrm{~min}$ & 1.3 & 4.4 & 0.2 & 0.4 \\
\hline$t=30 \min$ & 0.5 & 1.5 & 0.2 & 0.4 \\
\hline \multicolumn{5}{|l|}{ 4-t-OP (ng/mL) } \\
\hline $\mathrm{t}=0 \mathrm{~min}$ & 0.4 & 1.0 & 0.3 & 0.1 \\
\hline $\mathrm{t}=5 \mathrm{~min}$ & I & 1.1 & 0.1 & / \\
\hline $\mathrm{t}=10 \mathrm{~min}$ & / & 0.6 & I & I \\
\hline $\mathrm{t}=15 \mathrm{~min}$ & 1 & 0.4 & 1 & 1 \\
\hline $\mathrm{t}=30 \mathrm{~min}$ & l & 0.1 & I & I \\
\hline
\end{tabular}

(/):value is under the limit of quantification.

n.a.: not available 
Table 3: Concentrations of 4-t-OP, 4-NP, 4-t-OP1EO, 4-t-OP2EO, 4-NP1EO and 4NP2EO in influent and effluent samples, before and after ozone treatment and biological treatment. Influent samples are from Company 2.

\begin{tabular}{|c|c|c|c|c|c|c|}
\hline Concentration (ng/mL) & 4-NP & 4-t-OP & 4-NP1EO & 4-NP2EO & 4-t-OP1EO & 4-t-OP2EO \\
\hline \multicolumn{7}{|l|}{ Scheme 1} \\
\hline Influent (before applying $\mathrm{O}_{3}$ ) & 3.88 & 0.62 & 2.00 & 13.93 & 0.51 & 2.14 \\
\hline $\begin{array}{l}\text { Treated influent (after applying } \\
\left.\mathrm{O}_{3} \text { for } 15 \mathrm{~min}\right)\end{array}$ & 2.98 & 0.45 & 1.41 & 9.02 & 0.37 & 1.36 \\
\hline $\begin{array}{c}\text { Effluent (after applying } \mathrm{O}_{3}+ \\
\text { biological treatment) }\end{array}$ & 0.60 & 0.14 & / & 0.14 & / & 0.09 \\
\hline \multicolumn{7}{|l|}{ Scheme 2} \\
\hline $\begin{array}{c}\text { Influent (before biological } \\
\text { treatment) }\end{array}$ & 3.88 & 0.62 & 2.00 & 13.93 & 0.51 & 2.14 \\
\hline $\begin{array}{c}\text { Effluent (after biological } \\
\text { treatment) }\end{array}$ & 1.05 & 0.18 & / & 0.18 & / & 0.04 \\
\hline $\begin{array}{c}\text { Effluent (after biological } \\
\text { treatment }+\begin{array}{c}\text { applying } \mathrm{O}_{3} \text { for } 30 \\
\text { min) }\end{array}\end{array}$ & 0.26 & 0.04 & / & 0.17 & / & 0.08 \\
\hline \multicolumn{7}{|l|}{ Scheme 3} \\
\hline $\begin{array}{c}\text { Influent (before biological } \\
\text { treatment) }\end{array}$ & 3.88 & 0.62 & 2.00 & 13.93 & 0.51 & 2.14 \\
\hline $\begin{array}{c}\text { Effluent (after biological } \\
\text { treatment) }\end{array}$ & 1.05 & 0.18 & / & 0.18 & / & 0.04 \\
\hline $\begin{array}{c}\text { Effluent (after biological } \\
\text { treatment }+\begin{array}{c}\text { applying } \mathrm{O}_{3} \text { for } 60 \\
\text { min) }\end{array}\end{array}$ & I & / & 1 & 0.11 & 1 & 0.05 \\
\hline
\end{tabular}

(/): value is under the limit of quantification. 


\section{Supporting Information}

\section{Fast liquid chromatography-tandem mass spectrometry methodology for the analysis of alkylphenols and their ethoxylates in wastewater samples from the tank cleaning industry}

Mélanie Mignot ${ }^{1}$, Maarten Nagels ${ }^{2}$, Sven Poelmans ${ }^{3}$, Alexander Kensert ${ }^{1}$, Jan Dries ${ }^{3}$, Raf Dewil' ${ }^{2}$, Deirdre Cabooter ${ }^{1^{*}}$

${ }^{1} \mathrm{KU}$ Leuven, Pharmaceutical Analysis, Faculty of Pharmaceutical Sciences, O\&N II Herestraat 49, Leuven, Belgium

${ }^{2} \mathrm{KU}$ Leuven, Department of Chemical Engineering, Process and Environmental Technology Lab, J. De Nayerlaan 5, B-2860 Sint-Katelijne-Waver, Belgium

3 University of Antwerp, Bio-Chemical Green Engineering \& Materials, Faculty of Applied Engineering, Salesianenlaan 90, 2660 Antwerp, Belgium

$\left({ }^{*}\right)$ corresponding author:

tel.: (+) 32 (0)16.32.34.42, fax: (+) 32 (0)16.32.34.48, e-mail: deirdre.cabooter@kuleuven.be 


\section{Abstract}

The Supporting Information supplies three additional figures and three tables related to this study. Figure S1 represents the calibration curves for each compound. Figure S2 and S3 correspond to extracted ion chromatograms at the LOQ for 4-t-OP and 4-NP; and their mono and diethoxylates, respectively. Table S1 reports the optimized MS parameters for all compounds, and Table S2 supplies the data from the recovery study for all compounds spiked in influent and effluent wastewater from Company 2. Table S3 corresponds to recovery study performed in spiked milli-Q water

\section{Table of contents}

Figure S1: Calibration curves for 4-NP, 4-t-OP, 4-t-OP1EO, 4-t-OP2EO, 4-NP1EO, 4NP2EO

Figure S2: Extracted ion chromatograms at the limit of quantification for 4-t-OP, 4-NP and the internal standards.

Figure S3: Extracted ion chromatograms at the limit of quantification for 4-t-OP1EO, 4-t-OP2EO, 4-NP1EO, 4-NP2EO and the internal standards.

Table S1: MS optimized parameters for the alkylphenols and ethoxylates and their internal standards (IS). The first transition corresponds to the quantifier and the second one to the qualifier.

Table S2: Recoveries for 4-t-OP, 4-NP, 4-t-OP1EO, 4-t-OP2EO, 4-NP1EO, 4-NP2EO spiked in influent and effluent wastewater from Company 2 at different concentrations, with intra-day RSDs $(n=3)$.

Table S3: Recoveries for 4-t-OP, 4-NP, 4-t-OP1EO, 4-t-OP2EO, 4-NP1EO, 4-NP2EO in Milli-Q water with intra-day RSDs $(n=3)$ and inter-day RSDs $(n=9)$ at 3 concentration levels. 
Figure S1: Calibration curves for 4-NP, 4-t-OP, 4-t-OP1EO, 4-t-OP2EO, 4-NP1EO, 4NP2EO. (IS) refers to internal standard (4-(3,6-dimethyl-3-heptyl)phenol-ring- $\left.{ }^{13} \mathrm{C}_{6}\right)$ for 4-NP, 4-tert-octylphenol-ring- ${ }^{13} \mathrm{C}_{6}$ for 4-t-OP, 4-(3,6-dimethyl-3-heptyl)phenol monoethoxylate-ring- ${ }^{13} \mathrm{C}_{6}$ for 4-NP1EO and 4-(3,6-dimethyl-3-heptyl)phenoldiethoxylate-ring- ${ }^{13} \mathrm{C}_{6}$ for 4-NP2EO. 4-(3,6-dimethyl-3-heptyl)phenol monoethoxylatering- ${ }^{13} \mathrm{C}_{6}$ was used as IS for 4-t-OP1EO and 4-(3,6-dimethyl-3-heptyl)phenoldiethoxylate-ring- ${ }^{13} \mathrm{C}_{6}$ for 4 -t-OP2EO, respectively, to correct for instrumental variations. Error bars represent the standard deviations for alkylphenols $(n=5)$, and for the ethoxylates $(n=3)$.
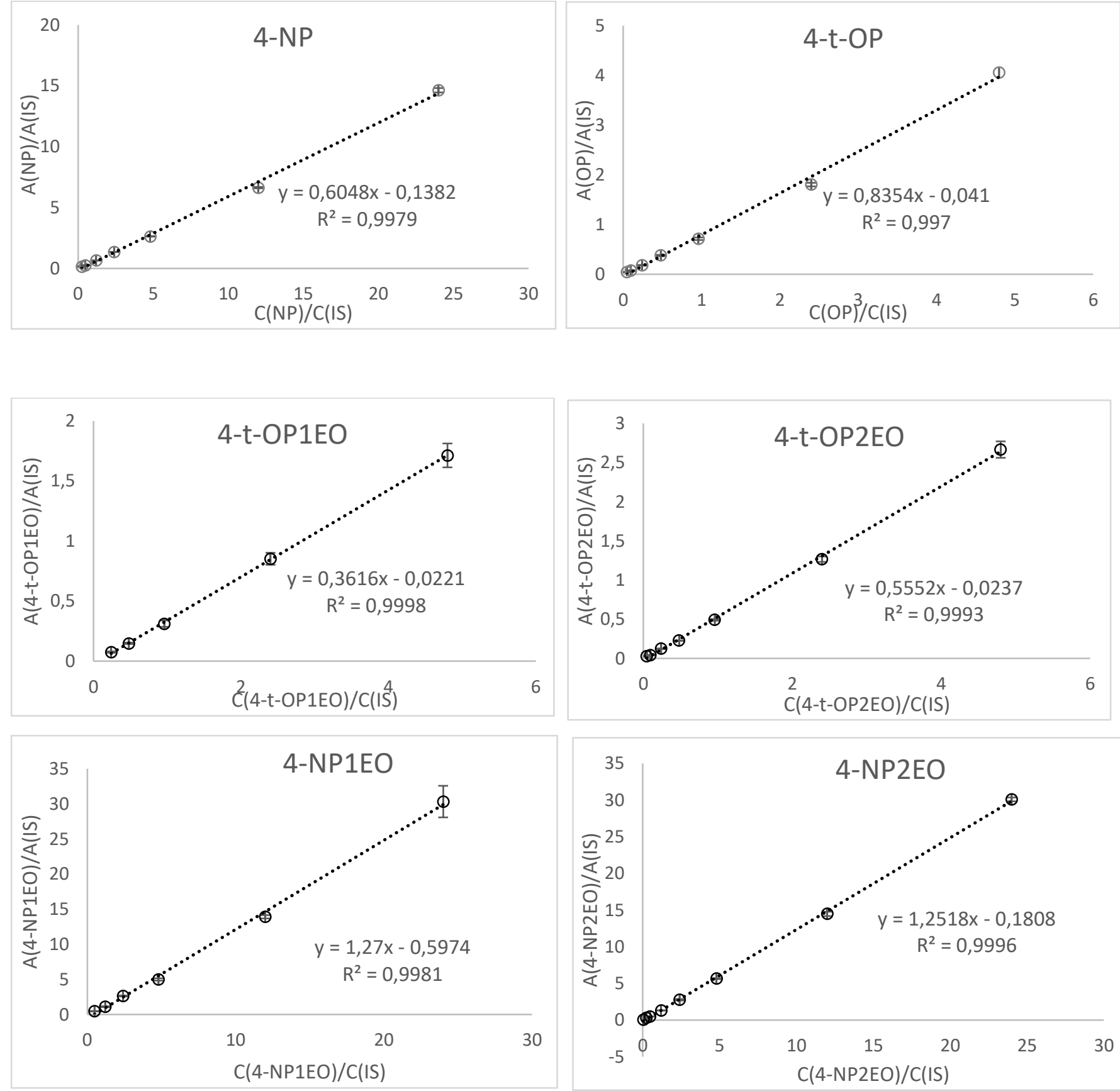
Figure S2: Extracted ion chromatograms at the limit of quantification for 4-t-OP, 4-NP and the internal standards.
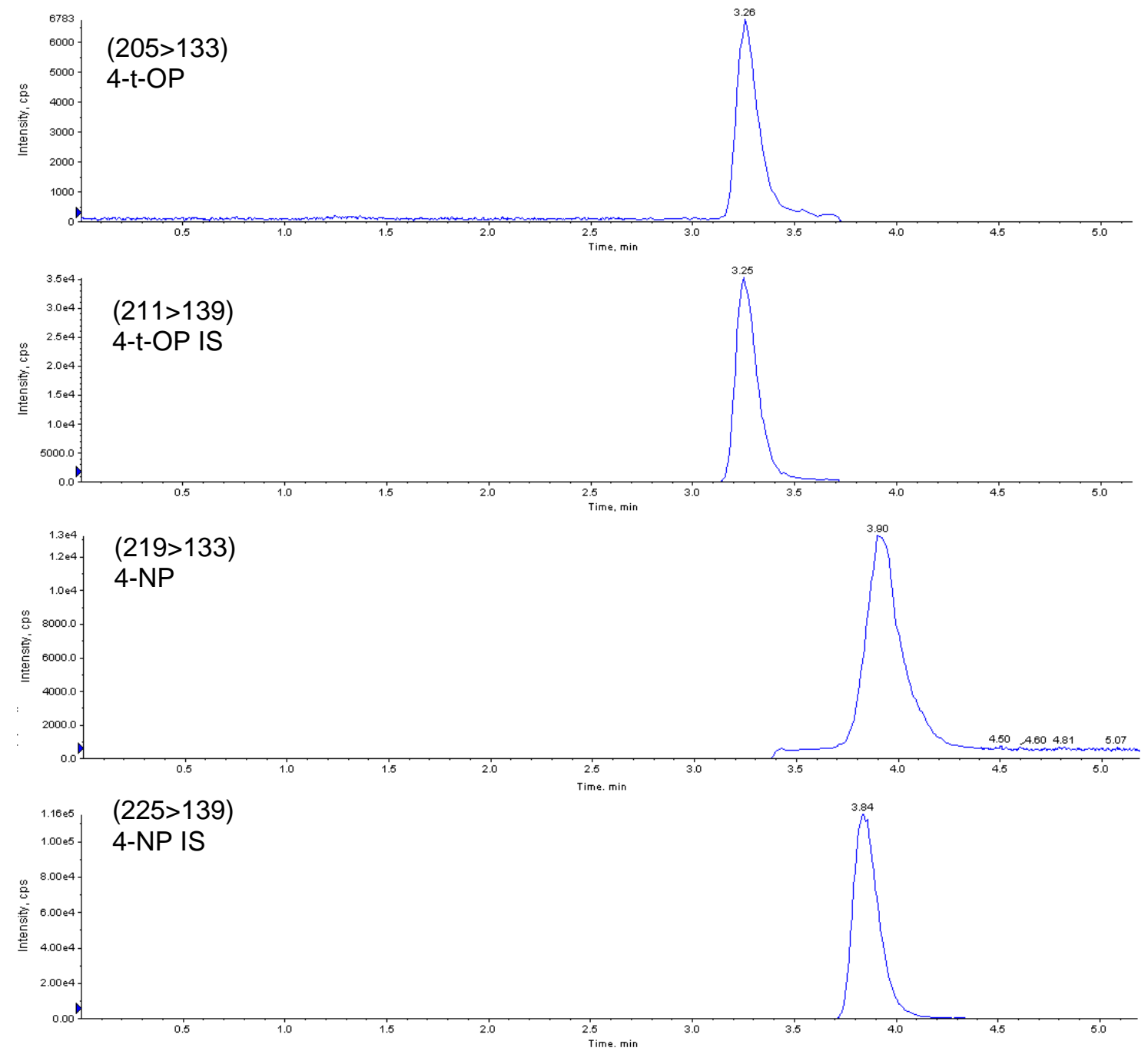
Figure S3: Extracted ion chromatograms at the limit of quantification for 4-t-OP1EO, 4-t-OP2EO, 4-NP1EO, 4-NP2EO and the internal standards.

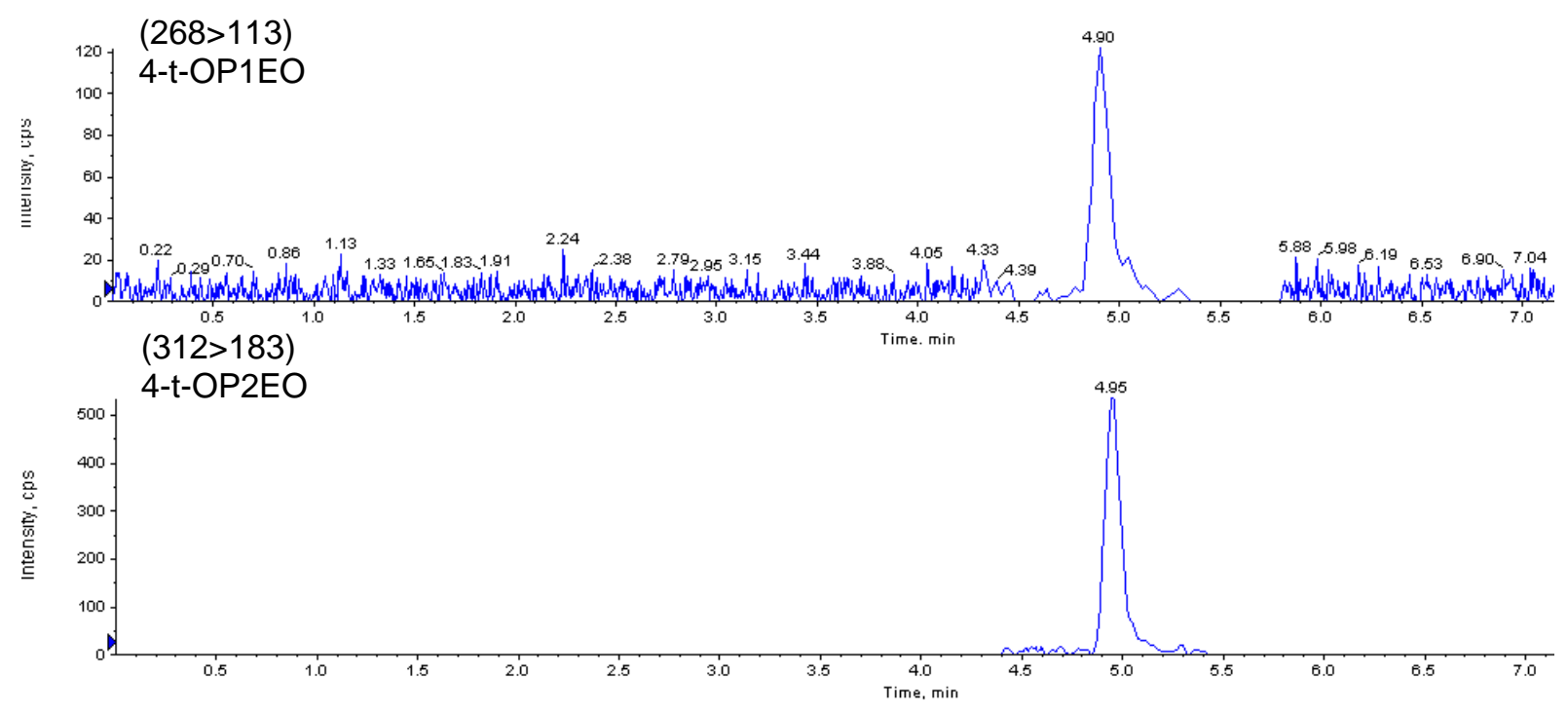

(282>127)

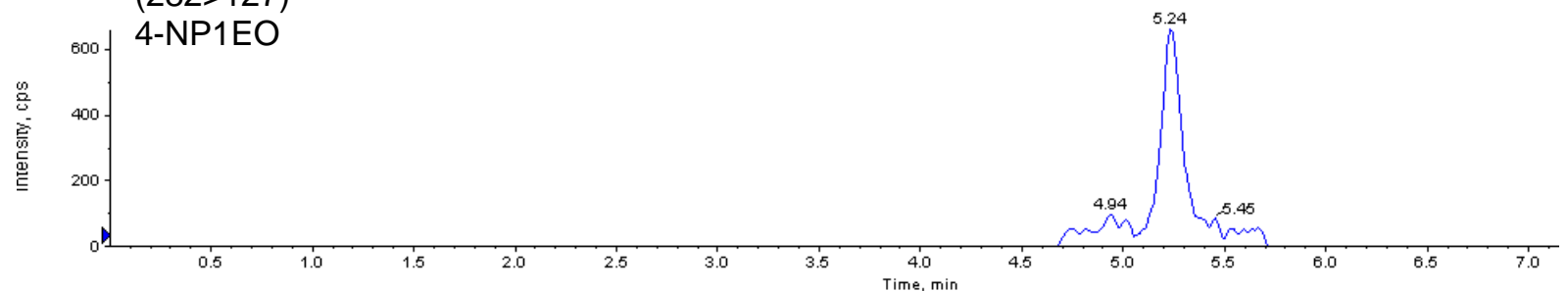

(326>183)



(288>127)

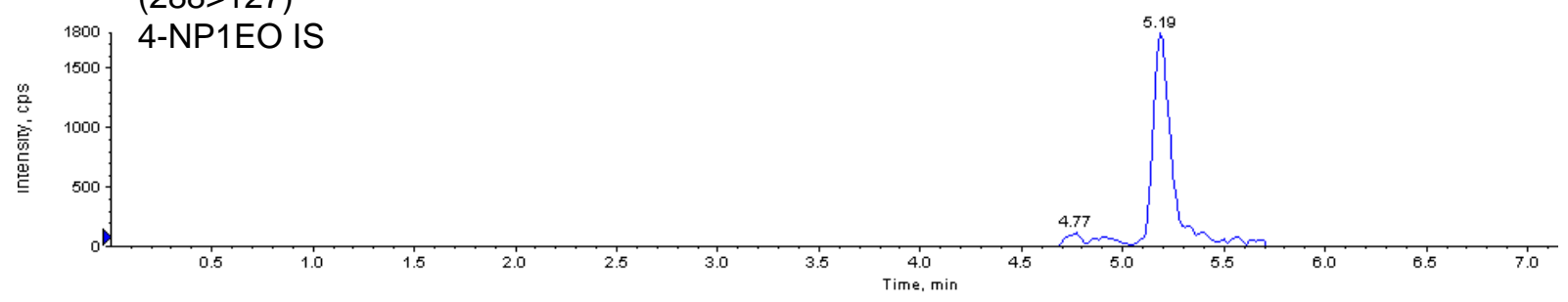

(332>189)

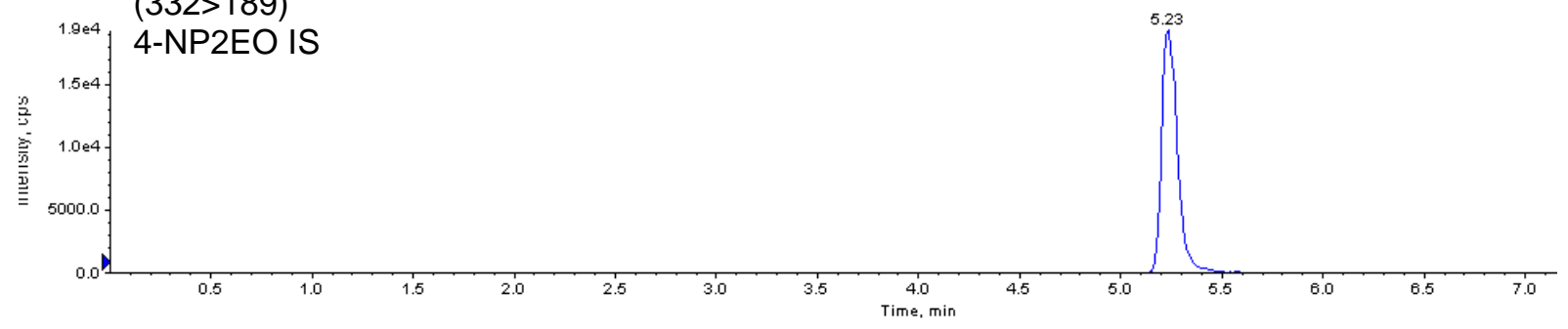


Table S1: MS optimized parameters for the alkylphenols and ethoxylates and their internal standards (IS). The first transition corresponds to the quantifier and the second one to the qualifier. (DP) is the declustering potential, (FP) the focusing potential, (EP) the entrance potential, (CE) the collision energy, and (CXP) the collision cell exit potential, (NEB), the nebulization gas, (CUR) the curtain gas, (CAD) the collision gas, (TEM) the temperature and (IS) the ionspray voltage.

\begin{tabular}{|c|c|c|c|c|c|c|c|c|c|c|c|c|}
\hline & $\begin{array}{c}\text { Transition } \\
\text { (Da) }\end{array}$ & $\begin{array}{l}\text { DP } \\
\text { (V) }\end{array}$ & $\begin{array}{l}\text { FP } \\
\text { (V) }\end{array}$ & $\begin{array}{l}\text { EP } \\
\text { (V) }\end{array}$ & $\begin{array}{l}\mathrm{CE} \\
(\mathrm{eV})\end{array}$ & $\begin{array}{c}\text { CXP } \\
\text { (V) }\end{array}$ & $\begin{array}{l}\text { NEB } \\
\text { (psi) }\end{array}$ & $\begin{array}{l}\text { CUR } \\
\text { (psi) }\end{array}$ & $\begin{array}{l}\text { CAD } \\
\text { (psi) }\end{array}$ & $\begin{array}{l}\text { Heater } \\
\text { gas } \\
(\mathrm{L} / \mathrm{min})\end{array}$ & $\begin{array}{l}\text { TEM } \\
\left({ }^{\circ} \mathrm{C}\right)\end{array}$ & IS (V) \\
\hline \multirow[t]{2}{*}{ 4-NP } & $(219>133)$ & -46 & -170 & -5 & -42 & -23 & 8 & 8 & 12 & 7 & 500 & -4500 \\
\hline & $(219>147)$ & -46 & -170 & -5 & -38 & -29 & 8 & 8 & 12 & 7 & 500 & -4500 \\
\hline \multirow[t]{2}{*}{ 4-t-OP } & $(205>133)$ & -40 & -200 & -5 & -35 & -23 & 8 & 8 & 12 & 7 & 500 & -4500 \\
\hline & $(205>117)$ & -60 & -220 & -4 & -75 & -22 & 8 & 8 & 12 & 7 & 500 & -4500 \\
\hline 4-NP (IS) & $(225>139)$ & -46 & -170 & -5 & -42 & -23 & 8 & 8 & 12 & 7 & 500 & -4500 \\
\hline 4-t-OP (IS) & $(211>139)$ & -40 & -200 & -5 & -35 & -23 & 8 & 8 & 12 & 7 & 500 & -4500 \\
\hline \multirow[t]{2}{*}{ 4-t-OP1EO } & $(268>113)$ & 20 & 50 & 12 & 10 & 10 & 9 & 6 & 6 & 7 & 300 & 5000 \\
\hline & $(268>251)$ & 60 & 80 & 4 & 10 & 30 & 9 & 6 & 6 & 7 & 300 & 5000 \\
\hline \multirow[t]{2}{*}{ 4-t-OP2EO } & $(312>183)$ & 100 & 100 & 4 & 10 & 30 & 9 & 6 & 6 & 7 & 300 & 5000 \\
\hline & $(312>121)$ & 1 & 50 & 12 & 30 & 30 & 9 & 6 & 6 & 7 & 300 & 5000 \\
\hline \multirow[t]{2}{*}{ 4-NP1EO } & $(282>127)$ & 20 & 100 & 8 & 10 & 10 & 9 & 6 & 6 & 7 & 300 & 5000 \\
\hline & $(282>265)$ & 20 & 100 & 4 & 10 & 10 & 9 & 6 & 6 & 7 & 300 & 5000 \\
\hline \multirow[t]{2}{*}{ 4-NP2EO } & $(326>183)$ & 100 & 50 & 4 & 10 & 10 & 9 & 6 & 6 & 7 & 300 & 5000 \\
\hline & $(326>121)$ & 80 & 100 & 12 & 30 & 10 & 9 & 6 & 6 & 7 & 300 & 5000 \\
\hline 4-NP1EO (IS) & $(288>127)$ & 20 & 100 & 8 & 10 & 10 & 9 & 6 & 6 & 7 & 300 & 5000 \\
\hline 4-NP2EO (IS) & $(332>189)$ & 100 & 50 & 4 & 10 & 10 & 9 & 6 & 6 & 7 & 300 & 5000 \\
\hline
\end{tabular}


Table S2: Recoveries for 4-t-OP, 4-NP, 4-t-OP1EO, 4-t-OP2EO, 4-NP1EO, 4-NP2EO spiked in influent and effluent wastewater from Company 2 at different concentrations, with intra-day RSDs ( $n=3)$. ND: not determined.

\begin{tabular}{|c|c|c|c|c|c|c|c|c|c|c|c|c|}
\hline \multirow[b]{3}{*}{ Conc. (ng/mL) } & \multicolumn{6}{|c|}{ Effluent wastewater } & \multicolumn{6}{|c|}{ Influent wastewater } \\
\hline & \multicolumn{2}{|c|}{ 4-NP } & \multicolumn{2}{|c|}{ 4-NP1EO } & \multicolumn{2}{|c|}{ 4-NP2EO } & \multicolumn{2}{|c|}{ 4-NP } & \multicolumn{2}{|c|}{ 4-NP1EO } & \multicolumn{2}{|c|}{ 4-NP2EO } \\
\hline & Recovery & \%RSD & Recovery & \%RSD & Recovery & \%RSD & Recovery & \%RSD & Recovery & $\%$ RSD & Recovery & \%RSD \\
\hline 1 & ND & ND & ND & ND & 89 & 14,3 & ND & ND & ND & ND & ND & ND \\
\hline 5 & 120 & 3,6 & ND & ND & 98 & 5,3 & 115 & 20,0 & ND & ND & ND & ND \\
\hline 10 & 84 & 5,6 & 85 & 12,2 & 82 & 5,8 & 110 & 5,5 & 118 & 8,1 & ND & ND \\
\hline 25 & 107 & 2,1 & 90 & 6,5 & 92 & 4,9 & 117 & 2,6 & 103 & 18,4 & 91 & 18,6 \\
\hline 50 & 93 & 0,9 & 83 & 2,6 & 87 & 4,2 & 121 & 1,8 & 95 & 7,1 & 97 & 8,0 \\
\hline 100 & 105 & 0,4 & 87 & 3,0 & 94 & 3,3 & 116 & 1,9 & 122 & 2,8 & 90 & 14,4 \\
\hline 250 & 109 & 2,6 & 88 & 3,9 & 89 & 0,8 & 111 & 1,3 & 123 & 7,9 & 82 & 7,1 \\
\hline
\end{tabular}

\begin{tabular}{|c|c|c|c|c|c|c|c|c|c|c|c|c|}
\hline & \multicolumn{4}{|c|}{ Effluent wastewater } & \multicolumn{4}{c|}{ Influent wastewater } \\
\hline & \multicolumn{4}{|c|}{ 4-t-OP } & \multicolumn{4}{|c|}{ 4-t-OP1EO } & 4-t-OP2EO & \multicolumn{2}{c|}{ 4-t-OP } & \multicolumn{2}{c|}{ 4-t-OP1EO } & \multicolumn{2}{c|}{ 4-t-OP2EO } \\
\hline Conc. (ng/mL) & Recovery & \%RSD & Recovery & \%RSD & Recovery & \%RSD & Recovery & \%RSD & Recovery & \%RSD & Recovery & \%RSD \\
\hline $\mathbf{1}$ & 81 & 7,2 & ND & ND & 121 & 10,0 & ND & ND & ND & ND & ND & ND \\
\hline $\mathbf{2}$ & 95 & 9,0 & 113 & 3,4 & 87 & 8,3 & 108 & 18,8 & ND & ND & ND & ND \\
\hline $\mathbf{5}$ & 86 & 1,0 & 108 & 20,0 & 124 & 1,5 & 83 & 7,9 & ND & ND & 114 & 19,6 \\
\hline $\mathbf{1 0}$ & 87 & 1,5 & 116 & 6,2 & 130 & 1,0 & 117 & 2,2 & 116 & 8,4 & 122 & 18,7 \\
\hline $\mathbf{5 0}$ & 87 & 0,7 & 110 & 4,0 & 112 & 2,5 & 98 & 1,7 & 82 & 8,0 & 104 & 2,9 \\
\hline
\end{tabular}


Table S3: Recoveries for 4-t-OP, 4-NP, 4-t-OP1EO, 4-t-OP2EO, 4-NP1EO, 4-NP2EO spiked in Milli-Q water, with intra-day RSDs and inter-day RSDs at 3 concentration levels, injected 3 times and at 3 independent days.

\begin{tabular}{|c|c|c|c|c|c|c|c|}
\hline \multicolumn{8}{|c|}{ 4-NP (\%) } \\
\hline \multirow{2}{*}{ Conc. (ng/mL) } & \multirow{2}{*}{ Recovery - day 1} & \multirow{2}{*}{ Recovery - day 2} & \multirow{2}{*}{ Recovery - day 3} & \multicolumn{3}{|c|}{ Intra-day RSD } & \multirow{2}{*}{\begin{tabular}{|c|} 
Inter-day RSD \\
$(\mathrm{n}=9)$ \\
\end{tabular}} \\
\hline & & & & day $1(n=3)$ & day $2(n=3)$ & day $3(n=3)$ & \\
\hline 50 & 102,6 & 111,3 & 97,5 & & & & \\
\hline 50 & 103,1 & 103,6 & 105,1 & 3,6 & 4,2 & 7,2 & 4,9 \\
\hline 50 & 109,5 & 111,9 & 112,6 & & & & \\
\hline 100 & 111,2 & 115,1 & 104,5 & & & & \\
\hline 100 & 100,5 & 114,3 & 101,7 & 5,2 & 8,7 & 1,5 & 5,9 \\
\hline 100 & 103,8 & 98,3 & 102,0 & & & & \\
\hline 250 & 94,4 & 102,9 & 96,4 & & & & \\
\hline 250 & 93,2 & 100,5 & 93,5 & 0,7 & 1,4 & 2,7 & 4,6 \\
\hline 250 & 94,0 & 103,1 & 91,3 & & & & \\
\hline \multicolumn{8}{|c|}{ Mean recovery for 4-NP ( 3 concentration levels, 3 days): $102,9 \%(R S D=6,7 \%)(n=27)$} \\
\hline \multicolumn{8}{|c|}{ 4-NP1EO (\%) } \\
\hline \multirow{2}{*}{ Conc. $(\mathrm{ng} / \mathrm{mL})$} & \multirow{2}{*}{ Recovery - day 1} & \multirow{2}{*}{ Recovery - day 2} & \multirow{2}{*}{ Recovery - day 3} & \multicolumn{3}{|c|}{ Intra-day RSD } & Inter-day RSD \\
\hline & & & & day $1(n=3)$ & day $2(n=3)$ & day $3(n=3)$ & $(n=9)$ \\
\hline 50 & 87,4 & 94,6 & 90,0 & & & & \\
\hline 50 & 80,2 & 102,6 & 93,1 & 4,4 & 4,5 & 1,8 & 7,5 \\
\hline 50 & 82,5 & 95,6 & 90,7 & & & & \\
\hline 100 & 96,8 & 101,0 & 93,9 & & & & \\
\hline 100 & 92,7 & 96,6 & 88,6 & 2,5 & 2,2 & 4,3 & 3,8 \\
\hline 100 & 96,9 & 99,1 & 96,4 & & & & \\
\hline 250 & 87,9 & 102,2 & 98,2 & & & & \\
\hline 250 & 92,9 & 105,4 & 102,7 & 3,7 & 3,0 & 3,9 & 5,7 \\
\hline 250 & 94,3 & 99,2 & 94,9 & & & & \\
\hline \multicolumn{8}{|c|}{ Mean recovery for 4-NP1EO ( 3 concentration levels, 3 days): $94,7 \%$ (RSD $=6,4 \%$ ) ( $n=27$ ) } \\
\hline \multicolumn{8}{|c|}{ 4-NP2EO (\%) } \\
\hline \multirow{2}{*}{ Conc. (ng/mL) } & \multirow{2}{*}{ Recovery - day 1} & \multirow{2}{*}{ Recovery - day 2} & \multirow{2}{*}{ Recovery - day 3} & \multicolumn{3}{|c|}{ Intra-day RSD } & Inter-day RSD \\
\hline & & & & day $1(n=3)$ & day $2(n=3)$ & day $3(n=3)$ & $(n=9)$ \\
\hline 50 & 80,4 & 89,8 & 95,1 & & & & \\
\hline 50 & 80,8 & 85,3 & 96,5 & 3,6 & 3,3 & 0,9 & 6,9 \\
\hline 50 & 85,7 & 90,7 & 95,0 & & & & \\
\hline 100 & 90,2 & 88,6 & 90,7 & & & & \\
\hline 100 & 92,6 & 90,5 & 89,1 & 3,0 & 1,4 & 0,9 & 1,8 \\
\hline 100 & 87,3 & 88,3 & 90,5 & & & & \\
\hline 250 & 84,7 & 90,2 & 89,5 & & & & \\
\hline 250 & 86,9 & 96,0 & 90,1 & 2,0 & 3,6 & 0,6 & 4,1 \\
\hline 250 & 83,5 & 90,2 & 90,6 & & & & \\
\hline & Mean recove & ry for 4-NP2EO 13 & concentration leve & (s, 3 days): 89 , & $2 \%(\mathrm{RSD}=4,6$ & $(n=27)$ & \\
\hline
\end{tabular}




\begin{tabular}{|c|c|c|c|c|c|c|c|}
\hline \multicolumn{8}{|c|}{ 4-t-OP (\%) } \\
\hline \multirow{2}{*}{ Conc. (ng/mL) } & \multirow{2}{*}{ Recovery - day 1} & \multirow{2}{*}{ Recovery - day 2} & \multirow{2}{*}{ Recovery - day 3} & \multicolumn{3}{|c|}{ Intra-day RSD } & \multirow{2}{*}{\begin{tabular}{|c|} 
Inter-day RSD \\
$(\mathrm{n}=9)$ \\
\end{tabular}} \\
\hline & & & & day $1(n=3)$ & day $2(n=3)$ & day $3(n=3)$ & \\
\hline 20 & 91,7 & 85,6 & 104,2 & & & & \\
\hline 20 & 87,3 & 90,6 & 95,8 & 5,2 & 2,8 & 6,2 & 6,2 \\
\hline 20 & 96,8 & 88,1 & 92,5 & & & & \\
\hline 50 & 80,7 & 82,7 & 81,1 & & & & \\
\hline 50 & 87,0 & 82,7 & 88,4 & 3,8 & 0,7 & 5,0 & 3,6 \\
\hline 50 & 83,4 & 83,8 & 88,7 & & & & \\
\hline 75 & 83,4 & 83,7 & 87,4 & & & & \\
\hline 75 & 86,8 & 84,0 & 90,4 & 2,1 & 0,6 & 2,7 & 2,8 \\
\hline 75 & 84,1 & 83,0 & 85,6 & & & & \\
\hline \multicolumn{8}{|c|}{ Mean recovery for 4-t-OP ( 3 concentration levels, 3 days): $87,4 \%(R S D=6,1 \%)(n=27)$} \\
\hline \multicolumn{8}{|c|}{ 4-t-OP1EO (\%) } \\
\hline \multirow{2}{*}{ Conc. (ng/mL) } & \multirow{2}{*}{ Recovery - day 1} & \multirow{2}{*}{ Recovery - day 2} & \multirow{2}{*}{ Recovery - day 3} & \multicolumn{3}{|c|}{ Intra-day RSD } & Inter-day RSD \\
\hline & & & & day $1(n=3)$ & day $2(n=3)$ & day $3(n=3)$ & $(n=9)$ \\
\hline 10 & 97,4 & 111,6 & 107,8 & & & & \\
\hline 10 & 85,5 & 97,9 & 99,5 & 7,4 & 8,4 & 8,9 & 9,2 \\
\hline 10 & 86,2 & 95,9 & 90,2 & & & & \\
\hline 20 & 98,7 & 100,1 & 97,3 & & & & \\
\hline 20 & 86,3 & 86,3 & 95,9 & 6,9 & 7,4 & 1,6 & 5,2 \\
\hline 20 & 95,5 & 94,8 & 94,3 & & & & \\
\hline 50 & 86,0 & 95,1 & 92,6 & & & & \\
\hline 50 & 94,2 & 96,5 & 100,5 & 6,4 & 3,8 & 4,2 & 4,6 \\
\hline 50 & 97,6 & 89,8 & 95,2 & & & & \\
\hline \multicolumn{8}{|c|}{ Mean recovery for 4-t-OP1EO ( 3 concentration levels, 3 days): $95,1 \%(R S D=6,6 \%)(n=27)$} \\
\hline \multicolumn{8}{|c|}{ 4-t-OP2EO (\%) } \\
\hline \multirow{2}{*}{ Conc. (ng/mL) } & \multirow{2}{*}{ Recovery - day 1} & \multirow{2}{*}{ Recovery - day 2} & \multirow{2}{*}{ Recovery - day 3} & \multicolumn{3}{|c|}{ Intra-day RSD } & Inter-day RSD \\
\hline & & & & day $1(n=3)$ & day $2(n=3)$ & day $3(n=3)$ & $(n=9)$ \\
\hline 10 & 89,5 & 90,5 & 83,6 & & & & \\
\hline 10 & 80,0 & 90,5 & 89,4 & 7,4 & 0,3 & 4,5 & 4,6 \\
\hline 10 & 92,4 & 91,0 & 91,1 & & & & \\
\hline 20 & 88,7 & 89,9 & 82,9 & & & & \\
\hline 20 & 89,8 & 89,8 & 84,5 & 1,8 & 0,4 & 1,1 & 3,4 \\
\hline 20 & 86,6 & 89,3 & 83,0 & & & & \\
\hline 50 & 87,0 & 86,8 & 87,0 & & & & \\
\hline 50 & 88,4 & 89,6 & 88,1 & 2,1 & 2,1 & 1,8 & 1,8 \\
\hline 50 & 84,8 & 86,1 & 85,0 & & & & \\
\hline & Mean recover & $y$ for 4-t-OP2EO (3 & concentration lev & ls, 3 days): 87 & $6 \%(\mathrm{RSD}=3$, & $(n=27)$ & \\
\hline
\end{tabular}

